\title{
THE RELATIONSHIP BETWEEN HEAD POSTURE AND SKELETAL ANTERO-POSTERIOR JAW RELATIONSHIPS IN DIFFERENT SEX GROUPS
}

\author{
Waleed El Sayed Refaat*
}

\begin{abstract}
Objectives: This study aimed at comparing head posture and skeletal antero posterior jaw relationship in different sex groups.

Materials and methods: the study group consisted of 505 lateral cephalograms representing skeletal groups of Class I,II, and III based on ANB angle.Each group was subdivided into two subgroups according to gender : subgroup 1 (females) and subgroup 2 (males). Several cephalometric parameters and head posture variable were measured on the cephalograms. Head posture variables were compared in different antero-posterior jaw relationship and different sex groups. Analysis of variance (ANOVA) and multivariate analysis were used for statistical analysis.
\end{abstract}

Results: In the total sample, the only significant difference in head posture variable between different skeletal classes was NSL_Ver $(\mathrm{P}<0.05)$ between Class II and Class III skeletal relationships. There were significant differences in most of the head posture variables between both genders in the total sample at different $\mathrm{P}$ levels.

Conclusion: Class II patients exhibited more head extension relative to the true vertical plane than Class III patients. Females exhibiting more head extension relative to the cervical column than males, more forward cervical inclination and more cervical curvature also were noticed in females than males in the total sample.

\section{INTRODUCTION}

The term head posture has been used randomly to describe the spatial relationships of the head with reference to the true vertical, the cervical column, or both. Cole $(1988)^{1}$. Head posture has been found to be related to nasorespiratory function $^{(2-6)}$. Temporomandibular dysfunction ${ }^{(7-10)}$, cervical vertebrae morphology ${ }^{(11-13)}$ and craniofacial morphology (14-19). Only a small number of studies with limited sample size or age range have been made to investigate the relationship between head posture and skeletal antero-posterior jaw relationships. Marcotte $(1981)^{20}$ conducted a study

\footnotetext{
* Associate Prof. Orthodontic Department, Faculty of Dentistry, Suez Canal University.
} 
on 136 patients with no regard to age and gender; he found significant correlations between head posture and antero-posterior jaw relationships.

D'Attilio et al. (2005) ${ }^{17}$ conducted a study on children only ,they found several differences in head posture variables among different anteroposterior skeletal relationships. It would be of importance to investigate if there is any direct or indirect relationship between antero-posterior skeletal pattern and head posture. So in this study, head posture variables were examined and compared in subjects with different antero-posterior jaw relationships, taking the effect of age into consideration.

\section{MATERIALS AND METHODS}

\section{Materials}

A total sample of adult 505 lateral cephalograms were included in the study. The inclusion criteria for the subjects enrolled in the study were:

1. No previous orthodontic or orthognathic surgical treatment.

2. No cervical spine disorder or deformity.

3. The first four cervical vertebrae are included in the lateral cephalogram.

\section{Classification According to Antero-Posterior Skeletal Relationship.}

Subjects were divided into three groups according to the antero-posterior skeletal relationship based on the value of ANB angle. Furthermore, subjects in each group were subdivided into two age groups; subgroup 1 included females and subgroup 2 included males.

\section{Group I: Class I skeletal relationship (ANB angle $=3^{\circ} \pm 1$ )}

This group comprised 184 subjects( with a mean ANB of $3.0^{\circ} \pm 0.82$ ) was subdivided into two subgroups: subgroup 1 consisted of 113 subjects. subgroup 2 consisted of 71 subjects.

\section{Group II: Class II skeletal relationship (ANB an- gle $>4$ degrees)}

This group comprised 177 subjects( with a mean ANB of $6.07^{\circ} \pm 1.19$ ) was subdivided into two subgroups. sub group 1 consisted of 102 subjects and subgroup 2 consisted of 75 subjects .

\section{Group III: Class III skeletal relationship (ANB angle $<2$ degrees)}

This group comprised 144 subjects (with a mean ANB of $-0.75^{\circ} \pm 1.93$ ) was subdivided into two subgroups. sub group 1 consisted of 78 subjects, and subgroup 2 consisted of 66 subjects .

\section{Methods}

Records for this study consisted of lateral cephalograms, which were taken by the

same operator with the subjects standing with the head in the natural head position and the teeth in occlusion. Twelve hard tissue cephalometric points were marked on acetate papers including nine points in the craniofacial area and three points in the cervical column area. Seven lines were considered, yielding 3 linear and 16 angular measurements (Figure 1).

\section{Reference Points and Lines of the Postural Variables fig (1)}

Reference points and lines of the postural variables on the head and cervical column were traced according to Solow and Tallgren (1976) ${ }^{14}$.

\section{The located points in the cervical column area were}

1. Cv2tg: Tangent point of OPT line on the odontoid process of the second cervical vertebra.

2. Cv2ip: The most inferior posterior point on the body of the second cervical vertebra.

3. Cv4ip: The most inferior posterior point on the body of the fourth cervical vertebra 


\section{The constructed lines were:}

1. Cervical vertebra tangent (CVT): Posterior tangent to the odontoid process through Cv4ip.

2. Odontoid process tangent (OPT): Posterior tangent to the odontoid process through Cv2ip

3. True vertical line (Ver): The left border of the cephalogram was used as the vertical reference line (Tallgren and Sollow, 1987) ${ }^{32}$.

4. Truehorizontal line(Hor): The line perpendicular to Ver.

\section{Head Posture Angles fig(2)}

Sollow and tallgren (1976) ${ }^{14}$ defined several postural angles:

\section{Craniovertical angulations}

1. NSL_Ver: Downward opening angle between NSL line and Ver line describes anterior cranial base inclination relative to the true vertical.

2. NL_Ver: Downward opening angle between NL line and Ver line describes maxillary base inclination relative to the true vertical.

3. ML_Ver: Downward opening angle between ML line and Ver line describes mandibular base inclination relative to the true vertical.

\section{Craniocervical angulations}

4. NSL_OPT: Downward opening angle between NSL line and OPT line describes anterior cranial base inclination relative to the cervical column.

5. NSL_CVT: Downward opening angle between NSL line and CVT line.

6. NL_OPT: Downward opening angle between NL line and OPT line describes Maxillary base inclination relative to the cervical column.
7. NL_CVT: Downward opening angle between NL line and CVT line.

8. ML_OPT: Downward opening angle between ML line and OPT line describes Mandibular base inclination relative to the cervical column.

9. MLCVT: Downward opening angle between ML line and CVT line.

\section{Cervicohorizontal angulations}

10. CVTJHor: Upward opening angle between Hor line and CVT line describes cervical column inclination relative to the true horizontal.

11. OPTHor: Upward opening angle between Hor line and OPT line.

\section{Cervical curvature (Lordosis angle)}

12. OPT_CVT: Downward opening angle between CVT line and OPT line.

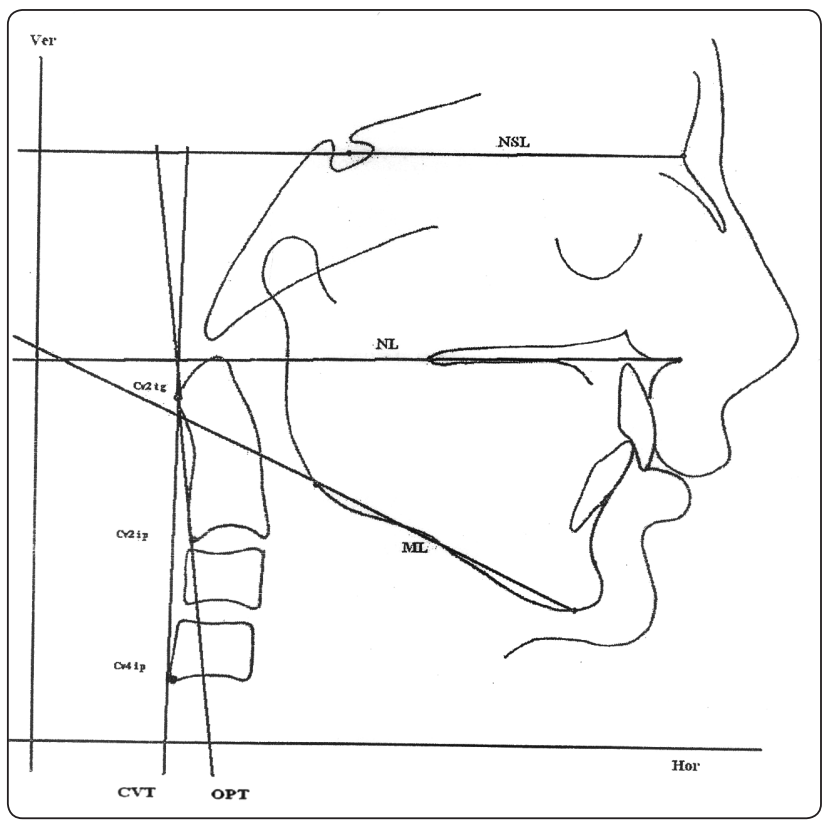

Fig. (1). Reference points and lines 


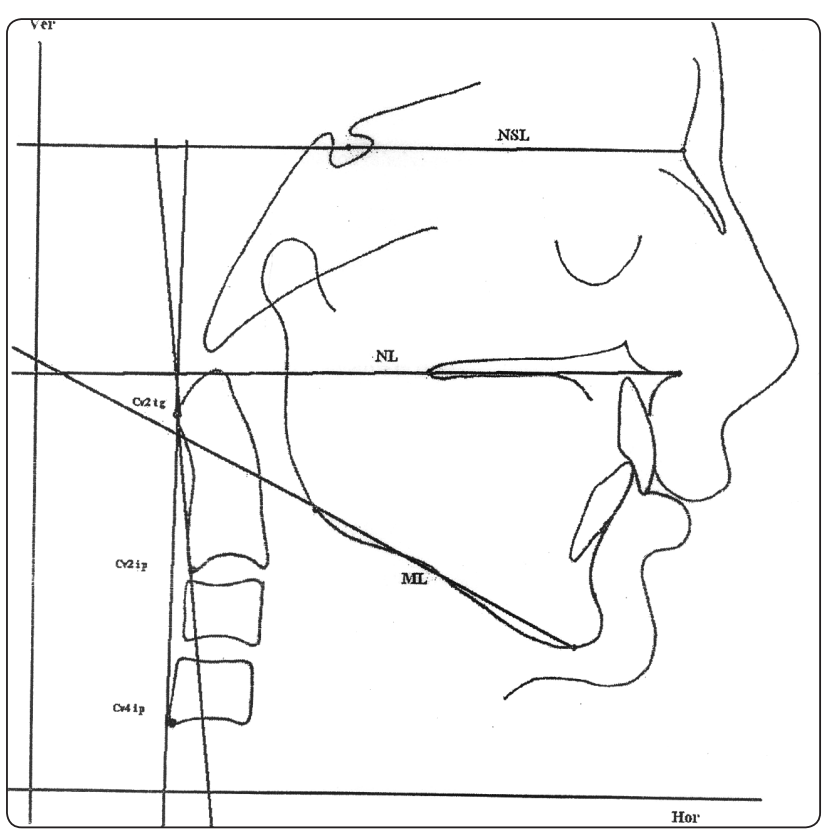

Fig. (2) Cephalometric drawing of head posture angles

1. NSL_Ver $\left(^{\circ}\right)$

2. NL_Ver $\left(^{\circ}\right)$

3. $\mathrm{ML}_{-} \operatorname{Ver}\left(^{\circ}\right)$

4. NSL_OPT $\left({ }^{\circ}\right)$

5. NSL_CVT $\left({ }^{\circ}\right)$

6. $\mathrm{NL}_{-} \mathrm{OPT} \mathrm{O}$

7. NL_CVT $\left({ }^{\circ}\right)$

8. $\mathrm{ML} \_\mathrm{OPT}\left({ }^{\circ}\right)$

9. $\mathrm{ML} \_\mathrm{CVT}\left({ }^{\circ}\right)$

10. CVT_Hor $\left(^{\circ}\right)$

11. OPT_Hor $\left({ }^{\circ}\right)$

12. OPT_CVTO

\section{Statistical Analysis}

Statistical analyses were performed using the Statistical Package for Social Science (SSPS version 16.00, Inc., Chicago, Illinois, USA). The mean and standard deviation were calculated for all measured variables. Analysis of variance (ANOVA) and multivariate analysis were used to determine if significant postural differences existed among the groups. The Bonferroni multiple comparison test was applied to the measurements to identify the differences between the groups. Statistical significance was set at $\mathrm{P}$ value $<0.05$.

\section{RESULTS}

\section{Head Posture Variables}

\section{Head Posture Variables for the Total Sample}

Mean and SD of the head posture variables for the total sample according to anteroposterior skeletal relationships, are shown in tables 1.

TABLE (1) Mean and SD for the head posture variables for the total sample.

\begin{tabular}{|l|c|c|}
\hline \multicolumn{3}{|c|}{$(\mathrm{n}=505)$} \\
\hline Head posture variables & Mean & SD \\
\hline NSL OPT $(*)$ & 102.77 & 10.47 \\
\hline NSL CVT(*) & 108.46 & 10.91 \\
\hline NSL Ver(*) & 105.82 & 7.08 \\
\hline NL OPT(*) & 94.42 & 10.16 \\
\hline NL CVT $\left(^{*}\right)$ & 100.26 & 9.75 \\
\hline NL Ver(*) & 97.52 & 6.97 \\
\hline ML OPT $(*)$ & 65.26 & 9.97 \\
\hline ML CVT $(*)$ & 70.92 & 9.51 \\
\hline ML Ver $(*)$ & 68.10 & 7.60 \\
\hline OPT Hor $(*)$ & 92.84 & 9.91 \\
\hline CVT Hor $(*)$ & 89.15 & 9.08 \\
\hline OPT CVT $(*)$ & 5.86 & 2.89 \\
\hline
\end{tabular}

$*$ p value $\leq 0.05$

\section{Head Posture Variables According to Antero- Posterior Skeletal Relationships}

There was a significant difference in NSL_ Ver angle between Class II and Class III skeletal relationships, $\left(2.60^{\circ}, \mathrm{P}<0.05\right)$. Class II exhibited higher angulation than Class III skeletal relationship indicating a more head extension relative to the true vertical in Class II subjects than Class III. The rest of the head posture 
variables showed no significant differences among different antero-posterior skeletal relationships. The differences and their level of significance are shown in table 2 .

\section{Head Posture Variables According to Gender}

There were significant differences in mostof the head posture variables between both genders in the total sample at different $\mathrm{P}$ levels. Females exhibited more head extension relative to cervical column than males (larger NSL_OPT and NSL_CVT), more forward cervical inclination (lesser OPT_Hor and CVT_Hor) and more cervical curvature(larger OPT_CVT). NL_CVT, ML_OPT and ML_CVT showed higher values in females indicating more upward inclination of the maxillary and mandibular bases relative to cervical column. NL_Ver showed lower values in females indicating more downward inclination of the maxillary base relative to the true vertical. NSL_Ver, NL_OPT, and ML_Ver showed no significant differences as showen in table 3 .

\section{Head Posture Variables According to Antero-Pos- terior Skeletal Relationships in both genders.}

Mean and SD of the head posture variables according to antero-posterior skeletal relationships in both genders subgroups are shown in tables 4 and 5. No significant differences were found regarding any of the head posture variables between different antero-posterior skeletal relationships within both genders.

TABLE (2) Mean and SD and difference in mean for the head posture variables according to antero--posterior skeletal relationships in the total sample.

\begin{tabular}{|c|c|c|c|c|c|c|c|c|c|}
\hline \multirow{3}{*}{$\begin{array}{c}\text { Head posture } \\
\text { variable }\end{array}$} & \multicolumn{6}{|c|}{ Antero-posterior skeletal relationships } & \multicolumn{3}{|c|}{ Mean different between classes } \\
\hline & \multicolumn{2}{|c|}{ Class I $(n=184)$} & \multicolumn{2}{|c|}{ Class II (n=177) } & \multicolumn{2}{|c|}{ Class III $(n=144)$} & \multirow{2}{*}{$\begin{array}{c}\mathrm{Cl} \mathrm{I}-\mathrm{Cl} \\
\text { II }\end{array}$} & \multirow{2}{*}{$\begin{array}{c}\mathrm{Cl} \mathrm{I-Cl} \\
\text { III }\end{array}$} & \multirow{2}{*}{$\begin{array}{c}\mathrm{Cl} \text { II-Cl } \\
\text { III }\end{array}$} \\
\hline & Mean & SD & Mean & SD & Mean & SD & & & \\
\hline NSL OPT $(*)$ & 103.12 & 10.48 & 103.61 & 10.65 & 101.28 & 10.14 & -0.49 & 1.84 & 2.33 \\
\hline NSL CVT(*) & 109.18 & 10.08 & 109.09 & 12.45 & 106.76 & 9.73 & 0.09 & 2.32 & 2.34 \\
\hline NSL Ver(*) & 106.05 & 6.42 & 106.86 & 7.41 & 104.26 & 7.27 & -0.81 & 1.79 & $2.60 *$ \\
\hline $\operatorname{NL~OPT}(*)$ & 94.21 & 10.42 & 95.02 & 10.22 & 93.96 & 9.79 & -0.81 & 0.25 & 1.06 \\
\hline $\operatorname{NLCVT}(*)$ & 100.24 & 10.11 & 101.05 & 9.85 & 99.33 & 9.47 & -0.81 & 0.91 & 1.72 \\
\hline NL Ver(*) & 97.25 & 6.78 & 98.28 & 7.08 & 96.94 & 7.03 & -1.03 & 0.91 & 1.34 \\
\hline $\operatorname{ML~OPT}(*)$ & 65.47 & 10.04 & 65.21 & 10.02 & 65.05 & 9.88 & 0.26 & 0.42 & 0.16 \\
\hline $\operatorname{MLCVT}(*)$ & 71.19 & 9.73 & 71.25 & 9.55 & 70.18 & 9.21 & -0.06 & 1.01 & 1.07 \\
\hline ML $\operatorname{Ver}(*)$ & 68.22 & 7.44 & 68.38 & 7.72 & 67.60 & 7.68 & -0.16 & 0.62 & 0.78 \\
\hline OPT Hor(*) & 92.86 & 9.48 & 92.74 & 10.17 & 92.92 & 10.17 & 0.12 & -0.06 & -0.18 \\
\hline CVT Hor(*) & 87.13 & 8.72 & 86.77 & 9.22 & 87.66 & 9.40 & 0.36 & -0.53 & -0.89 \\
\hline OPT CVT(*) & 5.94 & 2.94 & 6.08 & 2.90 & 5.48 & 2.78 & -0.14 & 0.47 & 0.60 \\
\hline
\end{tabular}

$*$ pvalue $\leq 0.05$ 
Table (3) Mean and SD and difference in mean for the head posture variables according to gender in the total sample.

\begin{tabular}{|c|c|c|c|c|c|}
\hline \multirow{3}{*}{ Head posture variables } & \multicolumn{4}{|c|}{ Gender } & \multirow{3}{*}{$\begin{array}{c}\text { Mean different between } \\
\text { groups }\end{array}$} \\
\hline & \multicolumn{2}{|c|}{$\begin{array}{c}\text { Female } \\
(n=293)\end{array}$} & \multicolumn{2}{|c|}{$\begin{array}{c}\text { Male } \\
(\mathrm{n}=212)\end{array}$} & \\
\hline & Mean & SD & Mean & SD & \\
\hline NSL OPT(*) & 103.73 & 9.97 & 101.50 & 11.02 & $2.23 *$ \\
\hline $\operatorname{NSL~CVT(*)~}$ & 109.81 & 11.10 & 106.60 & 10.39 & $3.21 * *$ \\
\hline NSL Ver(*) & 105.39 & 6.96 & 106.34 & 7.23 & -1.04 \\
\hline NL OPT(*) & 95.06 & 9.86 & 93.67 & 10.55 & 1.39 \\
\hline $\operatorname{NL~CVT(*)~}$ & 101.41 & 9.45 & 98.74 & 9.98 & $2.76^{* *}$ \\
\hline NL Ver(*) & 96.75 & 6.89 & 98.62 & 6.91 & $-1.87 * *$ \\
\hline ML OPT(*) & 66.55 & 9.63 & 63.53 & 10.18 & $3.02 * *$ \\
\hline $\operatorname{MLCVT}(*)$ & 72.60 & 9.05 & 68.57 & 9.65 & $4.03 * * *$ \\
\hline ML Ver(*) & 67.86 & 7.90 & 68.32 & 7.18 & -0.46 \\
\hline OPT Hor $(*)$ & 91.43 & 9.58 & 94.61 & 10.08 & $-3.18 * *$ \\
\hline CVT Hor $(*)$ & 85.28 & 8.63 & 89.70 & 9.06 & $-4.42 * * *$ \\
\hline OPT CVT(*) & 6.32 & 2.94 & 5.12 & 2.64 & $1.20 * * *$ \\
\hline
\end{tabular}

$*$ pvalue $\leq 0.05 \quad * *$ pvalue $\leq 0.01 \quad * * *$ pvalue $\leq 0.001$

TABLE (4) Mean and SD and difference in mean for the head posture variables according to antero-posterior skeletal relationship in females.

\begin{tabular}{|c|c|c|c|c|c|c|c|c|c|}
\hline \multirow{3}{*}{$\begin{array}{c}\text { Head posture } \\
\text { variable }\end{array}$} & \multicolumn{6}{|c|}{ females(n = 293) } & \multicolumn{3}{|c|}{ Mean different between classes } \\
\hline & \multicolumn{2}{|c|}{ Class I (n=113) } & \multicolumn{2}{|c|}{ Class II (n=102) } & \multicolumn{2}{|c|}{ Class III (n=78) } & \multirow{2}{*}{ Cl I-Cl II } & \multirow{2}{*}{ Cl I-Cl III } & \multirow{2}{*}{$\begin{array}{c}\mathrm{Cl} \text { III-Cl } \\
\text { III }\end{array}$} \\
\hline & Mean & SD & Mean & SD & Mean & $\mathrm{SD}$ & & & \\
\hline NSL OPT(*) & 103.28 & 10.39 & 105.54 & 9.83 & 101.82 & 9.21 & -2.26 & 1.46 & 3.72 \\
\hline $\operatorname{NSL~CVT(*)~}$ & 109.82 & 10.12 & 110.96 & 13.36 & 108.26 & 8.92 & -1.14 & 1.56 & 2.70 \\
\hline NSL Ver(*) & 104.95 & 6.61 & 106.95 & 6.80 & 103.92 & 7.33 & -2.00 & 1.03 & 3.03 \\
\hline NL OPT(*) & 94.07 & 10.34 & 96.38 & 10.02 & 94.38 & 8.78 & -2.31 & -0.31 & 2.00 \\
\hline $\operatorname{NLCVT}(*)$ & 100.57 & 10.13 & 102.77 & 9.07 & 100.62 & 8.79 & -2.20 & -0.05 & 2.15 \\
\hline NL Ver(*) & 95.85 & 6.70 & 97.77 & 6.72 & 96.37 & 7.27 & -1.92 & -0.52 & 1.40 \\
\hline ML OPT(*) & 66.30 & 10.07 & 67.06 & 9.51 & 66.19 & 9.20 & -0.76 & 0.11 & 0.87 \\
\hline $\operatorname{MLCVT}(*)$ & 72.39 & 9.64 & 73.45 & 8.82 & 71.99 & 8.46 & -1.06 & 0.40 & 1.46 \\
\hline ML Ver(*) & 67.74 & 7.84 & 68.37 & 7.87 & 67.57 & 8.09 & -0.63 & 0.17 & 0.80 \\
\hline OPT Hor(*) & 91.53 & 9.24 & 91.17 & 10.18 & 91.92 & 9.35 & 0.36 & -0.39 & -0.75 \\
\hline CVT Hor $(*)$ & 85.43 & 8.20 & 84.78 & 9.00 & 85.68 & 8.84 & 0.65 & -0.25 & -0.90 \\
\hline OPT CVT(*) & 6.41 & 3.09 & 6.47 & 3.07 & 6.28 & 2.57 & -0.06 & 0.13 & 0.19 \\
\hline
\end{tabular}


TABLE (5) Mean and SD and difference in mean for the head posture variables according to antero-posterior skeletal relationship in males.

\begin{tabular}{|c|c|c|c|c|c|c|c|c|c|}
\hline \multirow{3}{*}{$\begin{array}{c}\text { Head posture } \\
\text { variable }\end{array}$} & \multicolumn{6}{|c|}{ Age subgroup2 $(n=257)$} & \multicolumn{3}{|c|}{ Mean different between classes } \\
\hline & \multicolumn{2}{|c|}{ Class I (n=102) } & \multicolumn{2}{|c|}{ Class II ( $\mathrm{n}=85)$} & \multicolumn{2}{|c|}{ Class III ( $\mathrm{n}=61)$} & \multirow{2}{*}{ Cl I-Cl II } & \multirow{2}{*}{ Cl I-Cl III } & \multirow{2}{*}{$\begin{array}{c}\mathrm{Cl} \text { II-Cl } \\
\text { III }\end{array}$} \\
\hline & Mean & SD & Mean & SD & Mean & SD & & & \\
\hline NSL OPT(*) & 102.86 & 10.69 & 100.99 & 11.21 & 100.65 & 11.18 & 1.87 & 2.21 & 0.34 \\
\hline $\operatorname{NSL~CVT(*)}$ & 108.16 & 10.01 & 106.55 & 10.67 & 104.98 & 10.39 & 1.61 & 3.18 & 1.57 \\
\hline NSL Ver(*) & 107.80 & 5.70 & 106.73 & 8.21 & 104.65 & 7.24 & 1.07 & 3.15 & 2.08 \\
\hline NL OPT $(*)$ & 94.42 & 10.61 & 93.17 & 10.26 & 93.46 & 10.92 & 1.25 & 0.96 & -0.29 \\
\hline $\operatorname{NL~CVT}(*)$ & 99.70 & 10.14 & 98.70 & 9.82 & 97.80 & 10.07 & 1.00 & 1.90 & 0.90 \\
\hline NL Ver(*) & 99.47 & 6.33 & 98.98 & 7.54 & 97.62 & 6.72 & 0.49 & 1.85 & 1.36 \\
\hline $\operatorname{ML~OPT}(*)$ & 64.14 & 9.91 & 62.70 & 10.20 & 63.70 & 10.53 & 1.44 & 0.44 & -1.00 \\
\hline $\operatorname{MLCVT}(*)$ & 69.28 & 9.64 & 68.27 & 9.74 & 68.04 & 9.65 & 1.01 & 1.24 & 0.23 \\
\hline ML Ver(*) & 68.99 & 6.75 & 68.40 & 7.56 & 67.65 & 7.22 & 0.59 & 1.34 & 0.75 \\
\hline OPT Hor(*) & 94.97 & 9.55 & 94.88 & 9.83 & 94.10 & 11.02 & 0.09 & 0.87 & 0.78 \\
\hline CVT Hor(*) & 89.83 & 8.89 & 89.48 & 8.88 & 90.00 & 9.57 & 0.35 & -0.17 & -0.52 \\
\hline OPT CVT(*) & 5.19 & 2.54 & 5.56 & 2.59 & 4.55 & 2.74 & -0.37 & 0.64 & 1.01 \\
\hline
\end{tabular}

*pvalue $\leq 0.05$

\section{DISCUSION}

The aim of the present study was to investigate the relationship between head posture and anteroposterior skeletal relationships taking into consideration the gender. For that reason, the sample was subdivided into two subdivision based on gender. Marcotte (1981) ${ }^{20}$ using 136 subjects without regard to age found significant correlations between head posture and antero-posterior skeletal relationships. Other studies investigated the effect of antero-posterior skeletal relationships on head posture (Cole, 1988 ${ }^{1}$; D'Attilioetat.,2005 ${ }^{17}$ ). However, these studies were carried out on a relatively small sample size and young age groups.

\section{Head Posture Variables}

The means of the craniocervical, and cervical curvature angles in our sample were higher than those reported for the Danish sample by Solow and Sonnesen $(1998)^{30}$. On the other hand, the cervicohorizontal angles, showed relatively comparable means. These differences should be taken into consideration while studying head posture in Egyptians since postural variables may vary between different populations and different characteristics of the studied samples (Cooke and Wei, 1988a ${ }^{31}$; AlKofide and AINamankani, 2007) ${ }^{18}$.

\section{The Relationship between Head Posture and An- tero-posterior Jaw Relationships}

Considering the antero-posterior skeletal relationship of the jaws in head posture, subjects with skeletal Class II exhibited more head extension relative to the true vertical than Class III as indicated by the craniovertical angle (NSL_Ver). D'Artilio etal.(2005) ${ }^{17}$ reported no significant differences in craniovertical angle (NSL Ver) among the three skeletal classes. However, they reported a significant difference among the three skeletal classes regarding craniocervical angles with subjects in skeletal Class II exhibiting a significantly more extended head relative to the cervical column (Larger NSL_CVT) than subjects in skeletal Classes I and III. Generally both studies reported an association between 
skeletal Class II and head extension whether it is relative to the true vertical or the cervical spine. Although used different cephalometric method for assessing head posture, Marcotte (1981) ${ }^{20}$ reported similar result. He stated that people with a concave facial profile i.e. Class III skeletal relationship showed a tendency to flex the head to mask the prognathic mandible by forward posturing of the forehead, while people with a convex profile i.e. Class II skeletal relationship showed a tendency to extend the head to mask the convexity by increasing the prominence of the chin On the other hand, Cole $(1988)^{1}$ reported an association between head flexion (small NSL_Ver) with Class II skeletal relationship and head extension (large NSL_Ver) with Class III skeletal relationship. Cole $(1988)^{1}$ attributed this difference in the results to the fact that SNB is not a reliable indicator of mandibular prognathism. He explained the possibility of having small SNB associated with mandibular prognathism and large SNB associated with mandibular retrognathism. He pointed out to the relation between SNB and the inclination of NSL than to the prognathism of the mandible (i.e. the different spatial relationships of maxillaand mandible to the different orientations of NSL produce Class II and Class III relationships). He suggested that head extension is associated with retrognathic mandible and maxilla, and Class III relationships because the maxilla becomes more retrognathic than the mandible (Cole, 1988) ${ }^{1}$. Maxillary and mandibular position in relation to cranial base (SNA and SNB, respectively) showed significant negative correlations with craniovertical angle (NSL_Ver) and craniocervical angles (NSL_ CVT and NSL_OPT). This was in accordance with findings of Sollow and Tallgren $(1976)^{14}$. Additionally Cole $(1988)^{1}$ reported the same finding for NSL_Ver angle. Regarding craniocervical angles, Cole $(1988)^{1}$ reported negative correlations vith SNB in Class III only.Sollow and Tallgren $(1976)^{14}$ interpreted the negative correlation between SNA and SNB angles with craniovertical and craniocervical angles to mean that retrognathic jaws were seen in connection with head extension, and prognathic jaws in connection with head flexion. The negative correlation between SNA and SNB with craniovertical and craniocervical angles could be attributed to the relationship between head posture and air way dimensions. It had been reported that retrusion of the maxilla and mandible may lead to a narrower anteroposterior dimensions of the airway (Abu Allhaija and Al-Khateeb, 2005) ${ }^{23}$. Therefore, subjects with maxillary and mandibular retrusion would exhibit more head extension in order) increase air way dimensions since it has been reported that head extension lead to an increase in airway dimensions (Hellsing, 198924; Muto etal,2002 $2^{25}$ ).

\section{The Effect of Gender on Head Posture}

Females exhibited more head extension relative to the cervical column, more forward cervical inclination and more cervical curvature. NL_CVT, ML_OPT and ML_CVT angulations showed higher values in females since the maxillary and mandibular bases exhibited more upward inclination relative to the cervical column as a result from head extension. On the other hand NL_Ver showed lower values in females indicating more downward inclination relative to the true vertical. At first sight this might appear to be contradictory ( maxillary base showed more upward inclination relative to cervical column and more downward inclination relative to the true vertical),however, the explination lies in cervical inclination; maxillary base showed more upward inclination relative to the cervical column but at the same time the cervical column inclined more forward, this would lead to a downward inclination of the maxillary base relative to the true vertical.

Several authors reported that females exhibited a more forwardly inclined cervical column and more extended head relative to column (Huggar,1987) ${ }^{26}$ , (Cooke and Wei, 1988a) ${ }^{27}$. On the other hand, Sonnesen et al. $(2007)^{28}$ reported that females exhibited a more backwardly inclined cervical column than males. 
With regard to cervical curvature (OPT_CVT angle), a statistically significant difference was found between both genders; OPT_CVT was greater in females. The same result was found by Cooke and Wei (1988a) ${ }^{27}$ for both Caucasians and Chinese samples.

Several explanations for intersex differences in the postural variables were suggested including culturally based differences; this means that girls are encouraged to adopt a good upright posture and look straight head. Other possible factor is sexual dimorphism in cervical vertebral morphology i.e. the relative length of the cervical spine was larger in females which might lead to a more head extension in females (Cooke and Wei, 1988a) ${ }^{27}$.

\section{CONCLUSIONS}

1- Craniovertical, craniocervical, and cervical curvature angles in our sample were higher than those reported for the Danish sample.

2- Class II patients exhibited more head extension relative to the true vertical than Class III patients.

3- Females had a more forwardly inclined cervical spine and a more extended head relative to the spine.

\section{REFERENCES}

1- Cole, S.C. (1988). Natural head position, posture, and prognathism: the Chapman Prize Essay, 1986, British Journal of Orthodontics 15, 227-239.

2- Ricketts, R. M. (1968). Respiratory obstruction syndrome, American Journal of Orthodontics 54: 495-514.

3- Vig, P. S., Showfety, K. J., and Phillips, C. (1980). Experimental manipulation of head posture, American Journal of Orthodontics 77: 258-268.

4- Solow, B., Siersbak-Nielsen, S., and Greve, E. (1984). Air way adequacy, Head posture and craniofacial morphology, American Journal of Orthodontics 86: 214-223.

5- Huggare, J., and Laine-Alava, M. (1997).Nasorespiratory function and head posture, American Journal of Orthodontics and Dentofacial Orthopedics 112:507-11.
6- Cuccia, A., Lotti, M., and Caradonna, D. (2008). Oral Breathing and Head Posture, Angle Orthodontist 78:77-82.

7- Lee, W.Y., Okeson, J.P, and Lindroth, J.(1995).The relationship between forward head posture and tempromandibular disorders. Journal of Orofacial pain 9:161-167.

8- Gonzalez, H.E., and Manns, A. (1996). Forward head posture: its structural and functional influence on the stomatognathicsystem, a conceptual study. The Journal of Craniomandibular practice 14:71-80.

9- Sonnesen, L., Bakke, M, and Solow, B.(2001). Tempromandibular disdorders in relation to craniofacial dimensions, head posture and bite force in children selected for orthodontic treatment.Eurpean Journal of orthodontics 23:179-92.

10- Olmos, SR, Kritz-Silverstein, D, Halligan, W, and Silverstein, ST (2005). The effect of condyle fossa relationships on head posture. The Journal of Craniomandibular practice. 23: 48-52.

11- Kylämarkula, S., and Huggare, J. (1985). Head posture and the morphology of the first cervical vertebrae, European Journal of Orthodontics 7: 151 - 156.

12- Huggare, J., and Kylamarkula, S. (1985) Morphology of the first cervical vertebra in children with enlarged adenoids, European Journal of Orthodontics 7: 93-96.

13- Huggare, J. (1989). The first cervical vertebra as an indicator of mandibular growth, European Journal of Orthodontics 11:10-16.

14- Solow, B., and Tallgren, A. (1976). Head posture and craniofacial morphology, American Journal of Physical Anthropology 44:417-43.

15- Rocabado, M., Johnston,B,Blakney,M (1982).Physical therapy and dentistry :an overview.The Journal of Craniomandibular Practice:46-49.

16- Huggare, J,andHarkness, E.(1993). Associations between head posture and dental occlusion, Journal of Dental Research 72:255 (abstract).

17- D'Attilio, M., Caputi, S., Epifania, E., Festa, F., and Tecco, S. (2005). Evaluation of cervical posture of children in skeletal Class I, II, and III, The Journal of Craniomandibular Practice 23:219- 228.

18- AlKofide, E., and AINamankani, E. (2007). The association between posture of the head and malocclusion in Saudi subjects, The Journal of Craniomandibular Practice 25:98-105. 
19- Pachi, F., Turla, R., and Checchi, A.P. (2009). Head Posture and Lower Arch Dental Crowding, Angle Orthodontist 79:873-879.

20- Marcotte, M. R. (1981). Head posture and dentofacial proportions, Angle Orthodontist 51: 208-213.

21- Cooke, M.S., and Wei, S. H. Y. (1988a). Intersex differences in craniocervical morphology and posture in southern Chinese and British Caucasians, American Journal of Physical Anthropology 77:43-51.

22- Abu Allhaija, E.S., and Al-Khateeb, S.N. (2005).Uvuloglosso-pharyngeal dimensions in different anteroposterior skeletal patterns, Angle Orthodontist 75:1012-18.

23- Hellsing, E. (1989). Changes in the pharyngeal airway in relationito extension of the head,EuropeanJournal of Orthodontics 11:3 59-65.
24- Muto, T., Takeda, S., Kanazawa, M., Yamazaki, A., Fujiwara, Y., and Mizoguchi, I. (2002). The effect of head posture on the pharyngeal airway space (PAS), International Journal of Oral \& Maxillofacial Surgery 31: 579-583.

25- Huggare, J. (1987). A cross-sectional study of head posture and craniofacial growth in children from the north of Finland, Proceedings of the Finnish Dental Society 83:5-15.

26- Cooke, M.S., and Wei, S. H. Y. (1988a). Intersex differences in craniocervical morphology and posture in southern Chinese and British Caucasians, American Journal of Physical Anthropology 77:43-51.

27- Sonnesen,L., Pedersen, C.E., and Kjaer,I.(2007). Cervical column morphology related to head posture, cranial base angle, and condylar malformation, European Journal of Orthodontics 29:398-403. 